\title{
Rho GDP dissociation inhibitor $\alpha$ interacts with estrogen receptor $\alpha$ and influences estrogen responsiveness
}

\author{
Saad EI Marzouk ${ }^{1,3}$, Jennifer R Schultz-Norton ${ }^{3}$, Varsha S Likhite ${ }^{2,3}$, lan X McLeod ${ }^{4}$, \\ John R Yates ${ }^{4}$ and Ann M Nardulli ${ }^{3}$ \\ Departments of ${ }^{1} \mathrm{C}$ ell and Developmental Biology and ${ }^{2}$ Biochemistry, University of Illinois, Urbana, Illinois 61801, USA \\ ${ }^{3}$ Department of Molecular and Integrative Physiology, University of Illinois at Urbana-Champaign, 524 Burrill Hall, 407 South Goodwin Avenue, Urbana, Illinois 61801, USA \\ ${ }^{4}$ Department of Cell Biology, The Scripps Institute, 10550 North Torrey Pines Road, La Jolla, California 92037, USA \\ (Correspondence should be addressed to A M Nardulli; Email: anardull@life.uiuc.edu)
}

\begin{abstract}
Estrogen receptor $\alpha(E R \alpha)$ is a ligand-activated transcription factor that regulates expression of estrogen-responsive genes. Upon binding of the ligand-occupied ER $\alpha$ to estrogen response elements (EREs) in DNA, the receptor interacts with a variety of coregulatory proteins to modulate transcription of target genes. We have isolated and identified a number of proteins associated with the DNA-bound ER $\alpha$. One of these proteins, Rho guanosine diphosphate (GDP) dissociation inhibitor $\alpha($ RhoGDl $\alpha)$, is a negative regulator of the Rho family of GTP-binding proteins. In this study, we demonstrate that endogenously expressed RhoGDI $\alpha$ is present in the nucleus as well as the cytoplasm of MCF-7 breast cancer cells, and that RhoGDl $\alpha$ binds directly to $\mathrm{ER} \alpha$, alters the $\mathrm{ER} \alpha$-ERE interaction, and influences the ability of $\mathrm{ER} \alpha$ to regulate transcription of a heterologous estrogen-responsive reporter plasmid in transient transfection assays as well as endogenous, estrogen-responsive genes in MCF-7 cells. Our studies suggest that, in addition to the activity of RhoGDl $\alpha$ in the cytoplasm, it also influences $\mathrm{ER} \alpha$ signaling in the nucleus.
\end{abstract}

Journal of Molecular Endocrinology (2007) 39, 249-259

\section{Introduction}

Individual cells in multicellular organisms rely on a variety of signals from their surrounding environment to survive and function effectively. Neighboring and more distant cells produce a wide range of ligands including lipophilic hormones, peptides, and neurotransmitters that control various cellular functions ranging from metabolism, cell division, and differentiation to communication among cells from the same or different tissues. Once sensed by a cell, these ligands can initiate a cascade of intracellular events that oftentimes concludes with transcription factor activation and modulation of target gene expression. The receptors targeted by ligands can be intracellular such as steroid receptors or embedded in the cell membrane such as ligand-gated ion channels, receptor tyrosine kinase family members, or $\mathrm{G}$ protein-coupled receptors.

Rho GTP-binding proteins (RhoGTPases) are members of the Ras superfamily of GTP-binding proteins and are considered key players in the intracellular transmission of signals initiated by cellsurface receptors. RhoGTPases act as molecular switches cycling between an active, GTP-bound form, which is anchored to the cell membrane, and an inactive, GDP-bound form, which is present in the cytoplasm (Koch et al. 1997). When bound to GTP, RhoGTPases interact with downstream effector proteins and foster signal propagation. Once GTP is hydrolyzed, RhoGTPase activity ceases and signal transduction is halted. Proteins that regulate the activity of these molecular switches include GTPase-activating proteins (GAPs), which enhance the rate of GTP hydrolysis, GDP dissociation inhibitors (GDIs), which inhibit the release of GDP from the GTPase, and GDP exchange factors (GEFs), which replace GTPase-bound GDP with GTP. While GAPs and GDIs are negative regulators, GEFs are positive regulators of GTPase activity (Hart et al. 1992).

In addition to the signals initiated at the plasma membrane and propagated through the cytoplasm, some ligands, mainly lipophilic hormones, elicit their effects by targeting nuclear receptor superfamily members. In their classical mode of action, ligandoccupied nuclear receptors undergo a conformational change and interact with their cognate response elements in DNA to fulfill their function as transcription factors that regulate the expression of target genes. Through binding to specific nuclear receptors, lipophilic hormones regulate a variety of physiological processes. In addition to the traditional mode of nuclear receptor transactivation, there is accumulating evidence that receptors on the cell surface initiate 
signals that alter nuclear receptor activity. For example, epidermal growth factor (Kato et al. 1995, Bunone 1996 \#2283), transforming growth factor $\alpha$ (IgnarTrowbridge $e t$ al. 1993), and insulin-like growth factor-I (Ma et al. 1994) are able to alter the capacity of nuclear receptors to activate gene expression. This nonclassical mode of nuclear receptor regulation can be hormone independent or hormone dependent and provides a link between various cues received by receptors on the cell surface and the activity of receptors in the nucleus.

Our laboratory has been interested in identifying proteins that influence estrogen-responsive gene expression. Using agarose gel mobility shift assays and mass spectrometry analysis, we identified novel HeLa nuclear proteins associated with the DNA-bound estrogen receptor $\alpha$ (ER $\alpha$; Schultz-Norton et al. 2007). One of these ER $\alpha$-associated proteins was the $28 \mathrm{kDa}$ protein Rho GDP dissociation inhibitor $\alpha$ (RhoGDI $\alpha$ ), which was originally characterized as a negative regulator of the RhoGTPase family members RhoA, Rac1, and Cdc42 (Fukumoto et al. 1990, Leonard et al. 1992, Masuda et al. 1994, Koch et al. 1997, Olofsson 1999). Although the ability of RhoGDI $\alpha$ to enhance transcription of an estrogen response element (ERE)-containing reporter plasmid has been reported previously, it was thought that this enhanced activity was due to the cytoplasmic actions of RhoGDIa (Su et al. 2001, 2002). Because we found RhoGDI $\alpha$ associated with the DNA-bound $\mathrm{ER} \alpha$, we investigated the localization of endogenously expressed RhoGDI $\alpha$ in MCF-7 breast cancer cells and characterized the ability of this protein to interact with ER $\alpha$ and influence the expression of estrogen-responsive genes.

\section{Materials and Methods}

\section{Isolation of RhoGDla}

RhoGDI $\alpha$ was isolated with the ERE-bound ER $\alpha$ using HeLa nuclear extracts, purified ER, ERE-containing oligos, and agarose gel fractionation (Schultz-Norton et al. 2007). Five unique peptides (SIQEQELDKDDESLR, VAVSADPNVPNVVVTGLTLVCSSAPGPLELDLTGDLESFKK, IDKTDYMVGSYGPR, FTDDDKTDHLSWEWNLTIK, and AEEYEFLTPVEEAPK), which exclusively map to RhoG$\mathrm{DI} \alpha$, were identified by mass spectrometry analysis as described (Loven et al. 2003).

\section{Western blots}

Nuclear and cytosolic extracts were prepared from MCF7 and MDA-MB-231 breast cancer cells and U2 osteosarcoma (U2OS) cells as previously described (Wood et al. 2001). Ten micrograms of each extract were separated on a $15 \%$ SDS polyacrylamide gel and subjected to western analysis with an antibody directed against RhoGDI $\alpha, \mathrm{ER} \alpha$, or lamin $\mathrm{A} / \mathrm{C}$ (sc-360, sc-8002 and sc-20681 respectively, Santa Cruz Biotechnologies, Santa Cruz, CA, USA). The blots were then developed using a horseradish peroxidase-coupled secondary antibodies and a chemiluminescent detection system. The data included are representative of five different experiments.

\section{Subcloning, expression, and purification of his- tagged RhoGDl $\alpha$ protein for gel shift assays}

A $B a m \mathrm{H} 1 / E c o$ RI fragment of human RhoGDI $\alpha$ from pGST-GDI, kindly provided by M Garabedian (New York University, School of Medicine, New York), was subcloned into a dual-tagged (His and T7) pET-28a (+) vector (Novagen, La Jolla, CA, USA) for the expression of RhoGDI $\alpha$ protein. The plasmid was purified and used to transform Escherichia coli BL21-CodonPlus (DE3)-RIL competent cells (Stratagene, La Jolla, CA, USA) which were induced with $1 \mathrm{mM}$ IPTG at $37^{\circ} \mathrm{C}$ for $4 \mathrm{~h}$, chilled on ice for $5 \mathrm{~min}$, and pelleted at $4700 \mathrm{~g}$ for $10 \mathrm{~min}$ at $4{ }^{\circ} \mathrm{C}$. Ni-NTA lysis buffer $\left(50 \mathrm{mM} \mathrm{NaH}{ }_{2} \mathrm{PO}_{4}, 300 \mathrm{mM} \mathrm{NaCl}\right.$, and $10 \mathrm{mM}$ imidazole) was added to the cell pellet and the lysate obtained was sonicated on ice and centrifuged at $142000 \mathrm{~g}$ for $30 \mathrm{~min}$ at $4{ }^{\circ} \mathrm{C}$. The supernatant was diluted with one-half volume of Ni-NTA lysis buffer and incubated with Ni-NTA agarose beads (Qiagen) with rotation for $1 \mathrm{~h}$ at $4{ }^{\circ} \mathrm{C}$. The beads were washed thrice with Ni-NTA wash buffer $\left(50 \mathrm{mM} \mathrm{NaH}{ }_{2} \mathrm{PO}_{4}, 300 \mathrm{mM}\right.$ $\mathrm{NaCl}, 20 \mathrm{mM}$ imidazole, and $0.5 \%$ Triton X-100). His-RhoGDI $\alpha$ was eluted with Ni-NTA elution buffer (50 $\mathrm{mM} \mathrm{NaH}_{2} \mathrm{PO}_{4}, 300 \mathrm{mM} \mathrm{NaCl}$, and $250 \mathrm{mM}$ imidazole). Protein purity was monitored on Coomassiestained gels. Protein concentration was determined using the Bio-Rad protein assay (Bio-Rad) using BSA as a standard.

\section{Pull-down assay using purified proteins}

His, T7-tagged RhoGDI $\alpha$ was expressed and purified as described above using Ni-NTA. The purified protein was then immobilized on T7-Tag antibody agarose beads from T7-Tag Affinity purification kit (Novagen) according to the manufacturer's recommendation. Baculovirus expressed and purified $\mathrm{ER} \alpha$ was incubated with immobilized RhoGDI $\alpha$ at $4{ }^{\circ} \mathrm{C}$ for $1 \mathrm{~h}$ without or with $10 \mathrm{nM} 17 \beta$-estradiol $\left(\mathrm{E}_{2}\right)$. The beads were washed thrice with buffer provided in the purification kit and proteins were eluted with 2X SDS sample buffer (125 mM Tris pH 6.8, 4\% SDS, 20\% glycerol, $10 \%$ $\beta$-mercaptoethanol). Lysates from $E$. coli cells transformed with parental plasmid without RhoGDI $\alpha$ were purified in parallel. Western analysis was performed using a monoclonal antibody against ER $\alpha$ (sc-8002, Santa Cruz Biotechnologies). Similar results were obtained in three independent experiments. 


\section{Coimmunoprecipitation assays}

MCF-7 cells were grown to $80 \%$ confluency in $10 \mathrm{~cm}$ dishes in phenol red-free minimum essential medium (MEM, Invitrogen) containing 5\% charcoal-dextrantreated calf serum (CDCS) then maintained for $6 \mathrm{~h}$ in phenol red-free MEM containing $0 \cdot 4 \%$ fetal calf serum (FCS) before being treated for $24 \mathrm{~h}$ with $10 \mathrm{nM} \mathrm{E}_{2}$ or ethanol. The cells were washed thrice in cold 1X PBS and lysed in $500 \mu \mathrm{l}$ ice-cold lysis buffer $(20 \mathrm{mM}$ Tris $\mathrm{pH}$ 7.4, $10 \mathrm{mM}$ EDTA, $100 \mathrm{mM} \mathrm{NaCl}, 0 \cdot 5 \%$ IGEPAL, $1 \mathrm{mM}$ $\mathrm{Na}_{3} \mathrm{VO}_{4}, 50 \mathrm{mM} \mathrm{NaF}$, and $1 \mathrm{X}$ protease inhibitor cocktail (PIC, Sigma)). Equal amounts of the cell lysate were incubated with $1 \mu \mathrm{g}$ of fluorescein-specific antibody (University of Illinois, Immunological Resource Center, Urbana, IL, USA) or RhoGDI $\alpha$-specific antibody (sc-360, Santa Cruz Biotechnology) for $12 \mathrm{~h}$ at $4{ }^{\circ} \mathrm{C}$ under gentle agitation. Forty microlitres of $50 \%$ protein A sepharose slurry was added and the samples were rotated for $1 \mathrm{~h}$ at $4{ }^{\circ} \mathrm{C}$. The samples were then pelleted, washed thrice with wash buffer $(20 \mathrm{mM}$ Tris $\mathrm{pH} 7 \cdot 4$, $10 \mathrm{mM}$ EDTA, $100 \mathrm{mM} \mathrm{NaCl}, 0 \cdot 1 \%$ IGEPAL, $1 \mathrm{mM}$ $\mathrm{Na}_{3} \mathrm{VO}_{4}, 50 \mathrm{mM} \mathrm{NaF}$, and 1X PIC), and eluted with 2X SDS sample buffer for SDS-PAGE analysis followed by immunoblotting using an antibody against ER $\alpha$ (sc-8002, Santa Cruz Biotechnologies). The data shown are representative of four independent experiments.

\section{Transient transfections}

U2OS cells were maintained in phenol red-containing MEM with $10 \%$ FCS. Two days before plating, cells were transferred to phenol red-containing MEM supplemented with 5\% CDCS. After $24 \mathrm{~h}$, cells were transferred to phenol red-free MEM containing $5 \%$ CDCS. Cells were then seeded in 24 well plates at $2.5 \times 10^{4}$ cells/well and transfected with $20 \mathrm{ng}$ CMV5-hER $\alpha$ (Reese \& Katzenellenbogen 1991), $10 \mathrm{ng}$ TK-Renilla (Promega), and $1 \mu \mathrm{g}$ of a luciferase reporter vector containing two copies of the consensus ERE (2ERE-TK-Luciferase, kindly provided by $\mathrm{B}$ Katzenellenbogen, University of Illinois, Urbana, IL, USA) without or with 10-1000 ng of a RhoGDI $\alpha$ expression vector (pCDNA-RhoGDI $\alpha$, kindly provided by M Garabedian, New York University, School of Medicine, New York). A parental expression vector lacking the RhoGDI $\alpha$ sequence was used to maintain a constant amount of DNA in each well. Cells were transfected using lipofectin (Invitrogen) for $6 \mathrm{~h}$, after which they were treated with ethanol vehicle or $10 \mathrm{nM} \mathrm{E}_{2}$ for $24 \mathrm{~h}$. Luciferase activity was quantitated using the Dual Luciferase Assay kit (Promega). The data shown were derived from three independent experiments. Significant differences in luciferase activity were calculated by ANOVA using SAS.

\section{Gene silencing with RNA interference}

MCF-7 cells were maintained in phenol red-containing MEM supplemented with $5 \%$ calf serum and placed on phenol red-free MEM with 5\% CDCS $24 \mathrm{~h}$ prior to transfection. Cells were then seeded at $4 \times 10^{5}$ cells $/$ well in 12-well plates $24 \mathrm{~h}$ prior to transfection using phenol red-free MEM with 5\% CDCS without antibiotics and transfected with 50 pmol of control (renilla luciferase) or RhoGDI $\alpha$-specific siRNA oligos (4630 or 46085 respectively, Ambion, Austin, TX, USA) in the absence of antibiotics using siLenFect (Bio-Rad) for $24 \mathrm{~h}$. Media was replaced with phenol red-free, antibiotic-free MEM with $5 \%$ CDCS for an additional $24 \mathrm{~h}$ without or with $10 \mathrm{nM} \mathrm{E}_{2}$. Cells were then lysed in lysis buffer and western blot analysis was performed using antibodies to RhoGDI $\alpha$, ER $\alpha$, GAPDH (sc-360, sc-8002, and sc-20357 respectively, Santa Cruz Biotechnology), or PR (RM9102, LabVision, Fremont, CA, USA). RNA was harvested using Trizol (Invitrogen) and processed according to the manufacturer's directions. cDNA was synthesized using the Reverse Transcription System (Promega). Real-time PCR was performed using iQ SYBR Green Supermix and the iCycler PCR thermocycler (Bio-Rad) according to the manufacturer's directions. Primer sets for: GAPDH $\left(5^{\prime}-\mathrm{CGC}\right.$ TCT CTG CTC CTC CTG-3 $3^{\prime}$ and $5^{\prime}$-TCC GTT GAC TCC GAC CTT-3'), RhoGDI $\alpha$ (5'-ACC CAG CCA GGA ACA AAC-3 $3^{\prime}$ and $5^{\prime}$-GCA GAC ACA ACA CGA AGA C-3'), ER $\alpha\left(5^{\prime}\right.$-TGC CCT ACT ACC TGG AGA AC-3' and $5^{\prime}$ CCA TAG CCA TAC TTC CCT TGT C-3'), PR (5'-GTG CCT ATC CTG CCT CTC AAT C-3' and 5'- CCC GCC GTC GTA ACT TTC G-3'), and pS2 (5'-GCT GTT TCG ACG ACA CCG TT- ${ }^{\prime}$ and $5^{\prime}$-TTC TGG AGG GAC GTC GAT G-3') were utilized. Standard curves were derived using serial dilutions of cDNA equivalent to $0 \cdot 025,0 \cdot 25$, $2 \cdot 5$, and $25 \mathrm{ng}$ input RNA and were run in duplicate for each primer set during each experiment. The relative nanograms of RNA were determined from the standard curve. The average of three replicates from one experiment is shown which is representative of four independent experiments. Significant changes in RNA levels due to specific siRNA or hormone exposure were calculated by ANOVA using SAS 9.1 (SAS Institute Inc., Cary, NC, USA).

\section{Gel mobility shift assays}

Gel mobility shift assays were carried out as described previously with the following modifications. ${ }^{32} \mathrm{P}$-labeled, 50 bp ERE-containing oligos were incubated for $10 \mathrm{~min}$ at $4{ }^{\circ} \mathrm{C}$ in binding reaction buffer $(15 \mathrm{mM}$ Tris, $\mathrm{pH} 7 \cdot 9$, $20 \mathrm{mM} \mathrm{KCl}, 0 \cdot 2 \mathrm{mM}$ EDTA, $10 \%$ glycerol, $50 \mathrm{ng} / \mu \mathrm{l}$ poly

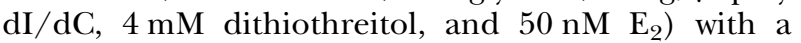
constant amount (50 fmoles) of baculovirus expressed, purified $\mathrm{ER} \alpha$, and increasing amounts of purified 
RhoGDI $\alpha$. BSA and Ni-NTA elution buffer were added as needed to maintain constant protein and salt concentrations. For antibody supershift experiments, ER $\alpha$ - and RhoGDI $\alpha$-specific antibodies (sc-8002 and sc-360 respectively, Santa Cruz Biotechnology) were added to the binding reaction mixture and incubated for an additional $10 \mathrm{~min}$ at room temperature. Samples were loaded onto a $6 \%$ nondenaturing polyacrylamide gel and fractionated using low ionic strength buffer as described previously (Chodosh \& Buratowski 1989). Radioactive bands were visualized by autoradiography. Three independent experiments were performed.

\section{Fluorescence microscopy}

MCF-7 cells were grown on poly-L-lysine-treated cover slips in phenol red-free MEM medium containing $5 \%$ CDCS and exposed to $10 \mathrm{nM} \mathrm{E} 2$ or ethanol vehicle for the indicated times. Cells were fixed in $1 \mathrm{X}$ PBS containing $4 \%$ formaldehyde and $4 \%$ sucrose for 10 min and permeabilized in $1 \mathrm{X}$ PBS with $0.2 \%$ Triton X-100 for 20 min. Blocking was performed in blocking buffer (2\% BSA, 2\% FBS, $0 \cdot 1 \%$ Tween-20, and $0 \cdot 02 \%$ $\mathrm{NaN}_{3}$ in 1X PBS) for $45 \mathrm{~min}$ at room temperature. When digitonin was used, the cells were first washed with transport buffer $(20 \mathrm{mM}$ HEPES $\mathrm{pH} 7 \cdot 4,110 \mathrm{mM}$ potassium acetate, $2 \mathrm{mM}$ magnesium acetate, and $0.5 \mathrm{mM}$ EGTA), then treated with $0.005 \%$ (wt/vol) digitonin in transport buffer for $6 \mathrm{~min}$ at $4{ }^{\circ} \mathrm{C}$. Cover slips were washed thrice in transport buffer and incubated for $20 \mathrm{~min}$ at room temperature before being fixed, permeabilized, and blocked as indicated above. Cells were incubated with rabbit polyclonal antibody against RhoGDI $\alpha$ (sc-360, Santa Cruz Biotechnology) alone or combined with either a mouse monoclonal antibody that recognizes a related family of NPC proteins (MMS-120P, Covance, Berkely, CA, USA) or a mouse monoclonal antibody that recognizes the nucleolar protein fibrillarin (Abcam Ab18380, Cambridge, MA, USA) in blocking buffer for $1 \mathrm{~h}$ at room temperature in a humidified box. Cells were washed thrice in 1X PBS with $0.1 \%$ Tween-20 and incubated with a fluorescein conjugated, donkey antirabbit secondary antibody, alone or combined with donkey anti-mouse, Texas Red conjugated, secondary antibody (Jackson Immunoresearch, West Grove, PA, USA) for $1 \mathrm{~h}$ at room temperature in a humidified box. The nuclei were counterstained with 4'-6-diamidino-2phenylindole and mounted with Vectashield mounting medium (Vector Labortories Inc., Burlingame, CA, USA). Digital images were captured by a charge-coupled device camera (Hamamatsu ORCA, Bridgewater, NJ, USA) mounted on a Nikon Microphot-SA microscope (Melville, NY, USA) using Openlab software 2.0.6 (Improvision I, Lexington, MA, USA). Montages of digital images were assembled in Adobe Photoshop 7.0.

\section{Results}

RhoGDI $\alpha$ has been described as a ubiquitously expressed protein, which is found primarily in the cytoplasm of cells (Koch et al. 1997). Thus, we were surprised when we identified endogenously expressed RhoGDI $\alpha$ from HeLa nuclear extracts as a component of a large multiprotein complex associated with the DNA-bound ER $\alpha$ (Schultz-Norton et al. 2007).

\section{RhoGDl $\alpha$ is present in the cytoplasm and the nucleus}

We undertook a series of experiments to monitor the localization of endogenously expressed RhoGDI $\alpha$ in cultured cell lines that have been used to study estrogen-responsive gene expression. As expected, RhoGDI $\alpha$ was detected in the cytosolic fractions (C) of ER $\alpha$-positive MCF-7 breast cancer cells in the absence and presence of $10 \mathrm{nM} \mathrm{E}_{2}$, ER $\alpha$-negative MDA-MB-231 breast cancer cells, and U2 osteosarcoma (U2OS) cells using western analysis (Fig. 1, lanes 2, 4, 6, and 8). RhoGDI $\alpha$ was also observed in the nuclear fractions $(\mathrm{N})$ of MCF-7 and U2OS cells (Fig. 1, lanes 1, 3, and 7). Although RhoGDI $\alpha$ was not visible in MDA-MD-231 nuclear extracts in the data shown, we were able to detect RhoGDI $\alpha$ in MDA-MB-231 nuclear extracts using higher antibody concentrations (data not shown). As expected, ER $\alpha$ was present only in MCF-7 cells. Lamin $\mathrm{A} / \mathrm{C}$ was used as a loading control to demonstrate that similar amounts of protein were loaded.

While our western analysis had demonstrated that RhoGDI $\alpha$ was present in MCF-7 and U2OS nuclear extracts, it seemed possible that homogenization of these cells could have resulted in the redistribution of some proteins. To examine the localization of endogenously expressed RhoGDI $\alpha$ in its native cell environment, immunocytochemistry (ICC) was performed in MCF-7 cells using a RhoGDI $\alpha$-specific antibody.

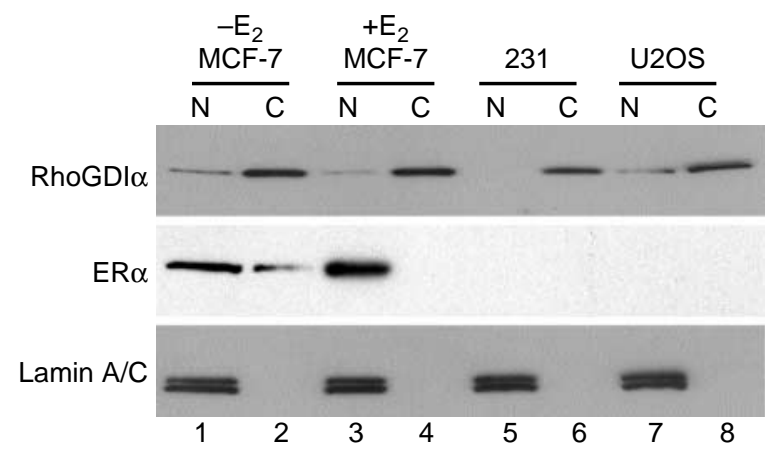

Figure 1 Western blot analysis of RhoGDl $\alpha$ in cultured cells. Nuclear (N, lanes 1, 3, 5, 7) and cytosolic (C, lanes 2, 4, 6, 8) extracts $(10 \mu \mathrm{g})$ from MCF-7, MDA-MB-231, and U2OS cells were tested for the presence of RhoGDI $\alpha$ and ER $\alpha$ using western analysis. Lamin $\mathrm{A} / \mathrm{C}$ was used as a loading control. 
As anticipated, RhoGDI $\alpha$ was found predominantly in the cytoplasm, but was also present in the nucleus (Fig. 2A). The localization of RhoGDI $\alpha$ was largely unaffected when MCF-7 cells were treated with ethanol vehicle or $10 \mathrm{nM} \mathrm{E}_{2}$ for 20 min or $24 \mathrm{~h}$. No staining was observed when primary antibody was omitted or when primary antibody was preincubated with a tenfold excess of bacterially expressed, purified RhoGDIa (data not shown).

To confirm that RhoGDI $\alpha$ was present in MCF-7 nuclei, cells were treated with digitonin for 6 min to permeabilize the plasma membrane but not the nuclear envelope, so that soluble proteins such as RhoGDI $\alpha$ could diffuse out of the cytoplasm. The boundary of the nuclear compartment was defined by an antibody that recognizes a related family of nuclear pore complex (NPC) proteins (Fig. 2B). Although no RhoGDI $\alpha$ was detected in the cytoplasm after digitonin treatment, it was present in the nuclei and appeared to be more concentrated in the nucleoli in the merged RhoGDIa and NPC images. The presence of RhoGDI $\alpha$ in the nucleoli was confirmed by its colocalization with the nucleolar protein fibrillarin in the merged images (Fig. 2C).

\section{RhoGDI $\alpha$ expression in MCF-7 cells is not affected by $E_{2}$ treatment}

To assess whether exposure of MCF-7 cells to $\mathrm{E}_{2}$ affected the level of RhoGDI $\alpha$, cells were treated with ethanol vehicle or $10 \mathrm{nM} \mathrm{E}_{2}$ for $0 \cdot 3,2,24,48$, or $72 \mathrm{~h}$ and whole
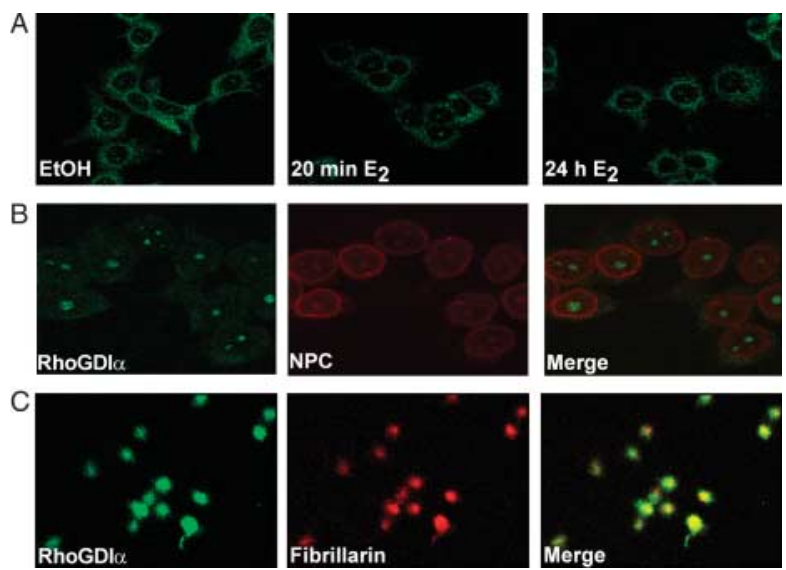

Figure 2 Subcellular distribution of endogenous RhoGDl $\alpha$ in MCF-7 cells. (A) MCF-7 cells were treated with ethanol or $10 \mathrm{nM}$ $\mathrm{E}_{2}$ for the indicated times and subjected to ICC analysis with a RhoGDI $\alpha$-specific antibody. (B and C) MCF-7 cell plasma membrane was partially permeabilized with digitonin before being subjected to ICC analysis using an antibody directed against RhoGDl $\alpha$, nuclear pore complex proteins (NPC), or the nucleolar protein fibrillarin. The merged images of RhoGDl $\alpha$ and NPC (B) and RhoGDl $\alpha$ and fibrillarin $(C)$ are shown. cell extracts were subjected to western analysis. No detectable changes in RhoGDI $\alpha$ protein levels were observed with any of the $\mathrm{E}_{2}$ treatments examined (Fig. 3). In contrast, ER $\alpha$ levels were decreased after $24 \mathrm{~h}$ and remained low as previously reported (Petz et al. 2004b). GAPDH, which was used as a loading control, was unaffected by hormone treatment.

\section{RhoGDI $\alpha$ enhances estrogen-mediated transactivation in U2OS cells}

Since RhoGDI $\alpha$ was originally identified in a complex with the ERE-bound ER $\alpha$ (Schultz-Norton et al. 2007) and we had detected endogenously expressed RhoGDI $\alpha$ in MCF-7 nuclei, we determined whether RhoGDI $\alpha$ could influence ER $\alpha$-mediated transactivation. Transient transfections were carried out in U2OS cells using an ER $\alpha$ expression vector, a luciferase reporter plasmid containing two copies of the consensus ERE, and a renilla reporter plasmid, which was used as an internal control. As increasing amounts of a RhoGDI $\alpha$ expression vector were included, a dosedependent increase in $\mathrm{E}_{2}$-mediated transactivation was observed (Fig. 4). These findings are in agreement with previous transfection experiments carried out in U2OS cells (Su et al. 2001).

\section{RhoGDl $\alpha$ alters endogenous expression of estrogen- responsive genes in MCF-7 cells}

Our transient transfection studies indicated that overexpression of RhoGDI $\alpha$ increased ER $\alpha$-mediated transactivation of a reporter gene containing a simple promoter and two tandem EREs. In order to study the effect of endogenously expressed RhoGDI $\alpha$ on transcription of native estrogen-responsive genes, RhoGDI $\alpha$ expression was knocked down in MCF-7 cells using small interfering RNA (siRNA) directed against exon 6 of RhoGDI $\alpha$. In addition siRNA directed against renilla

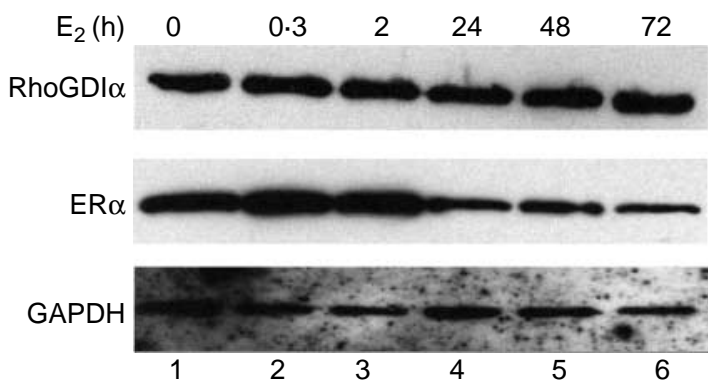

Figure 3 Levels of ER $\alpha$ and RhoGDl $\alpha$ after exposure of MCF-7 cells to $E_{2}$. MCF-7 cells were treated with ethanol or $10 n M E_{2}$ for the indicated times. Whole cell extracts were analyzed by western analysis with a RhoGDI $\alpha$ - or ER $\alpha$-specific antibody. GAPDH was included as a loading control. 


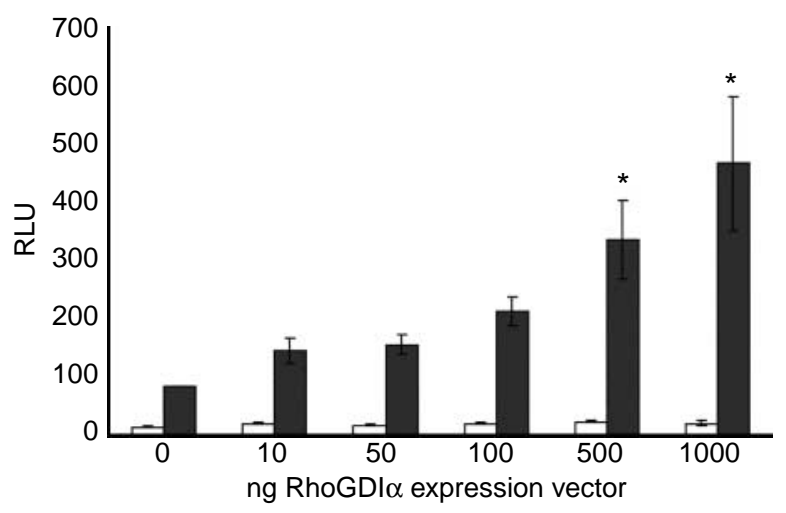

Figure 4 Effect of RhoGDl $\alpha$ on the expression of an estrogenresponsive reporter plasmid. U2OS cells were transiently transfected with a constant amount of an $E R \alpha$ expression vector, a reporter plasmid containing two consensus EREs, and increasing amounts of a RhoGDl $\alpha$ expression vector in the absence (open bars) or in the presence (solid bars) of $E_{2}$. An asterisk indicates that estrogen responsiveness was significantly greater $(P \leq 0.05)$ in the presence than in the absence of the RhoGDl $\alpha$ expression vector.

luciferase was used as a control. RhoGDI $\alpha$ mRNA levels were reduced when RhoGDI $\alpha$-specific, but not control, siRNA was used regardless of hormone exposure (Fig. 5A).When control siRNA was used, the levels of $\mathrm{PR}$ and $\mathrm{pS} 2 \mathrm{mRNA}$ were increased in the presence of $\mathrm{E}_{2}$ and the level of ER $\alpha$ mRNA was decreased. These findings are consistent with previous reports on the effects of $\mathrm{E}_{2}$ on PR and pS2 gene expression in MCF-7 cells (Nardulli et al. 1988, Kim et al. 2000). When RhoGDI $\alpha$ expression was decreased, there was an increase in the level of PR mRNA and a decrease in the level of pS2 mRNA in the presence of $\mathrm{E}_{2}$ when compared with the control siRNA. Interestingly, ER $\alpha$ mRNA levels were substantially increased in the absence of $\mathrm{E}_{2}$ when RhoGDI $\alpha$ was knocked down. GAPDH, which was used as an internal control, was unaffected by control or RhoGDI $\alpha$ siRNA. Taken together, these data demonstrate that RhoGDI $\alpha$ differentially influences the expression of endogenous, estrogen-responsive genes in MCF-7 cells.

We also monitored the effect of knocking down RhoGDI $\alpha$ on RhoGDI $\alpha$, ER $\alpha$, and PR protein levels using western blot analysis. RhoGDI $\alpha$ levels were dramatically reduced when siRNA targeting RhoGDI $\alpha$ was used (Fig. 5B, compare lanes 1 and 2 with lanes 3 and 4) indicating that the RhoGDI $\alpha$ siRNA was effective in decreasing the levels of RhoGDI $\alpha$ mRNA and protein. When control siRNA was used, the level of $\mathrm{ER} \alpha$ protein was decreased and the level of PR protein was increased in the presence of $\mathrm{E}_{2}$ (lanes 1 and 2) as previously reported (Petz et al. 2004b). When RhoGDI $\alpha$-specific siRNA was used, ER $\alpha$ protein levels were increased in the absence of hormone (compare lanes 1 and 3) and PR protein levels were increased in the presence of $\mathrm{E}_{2}$ (compare lanes 2 and 4). These findings are consistent with our RNA analysis. The level of GAPDH, which was used as an internal control, was unaffected by RhoGDI $\alpha$ expression.

\section{RhoGDI $\alpha$ and ER $\alpha$ interact}

To this point we had shown that RhoGDI $\alpha$ was present in the nuclei of MCF-7 cells and that altering RhoGDI $\alpha$ expression influenced estrogen-responsive gene expression. However, the mechanism by which RhoGDI $\alpha$ might influence ER $\alpha$-mediated transactivation remained unclear. It has been hypothesized that RhoGDI $\alpha$ might alter estrogen responsiveness through cytoplasmic RhoGDI $\alpha$ signaling ( $\mathrm{Su}$ et al. 2002). However, the presence of RhoGDI $\alpha$ and ER $\alpha$ in the nucleus of MCF-7 cells and the association of RhoGDI $\alpha$ with the DNA-bound ER $\alpha$ in our agarose gel shift assays suggested that RhoGDI $\alpha$ might interact with $\mathrm{ER} \alpha$ and influence its activity. Thus, coimmunoprecipitation experiments were carried out to determine whether endogenously expressed RhoGDI $\alpha$ and ER $\alpha$ interacted in MCF-7 cells. As seen in Fig. 6A, ER $\alpha$ was associated with RhoGDI $\alpha$ in MCF-7 cells in the absence and presence of $\mathrm{E}_{2}$ when an antibody against RhoGDIa (lanes 5 and 6), but not when a control antibody directed against fluorescein (lanes 3 and 4), was used.

To determine whether the receptor and RhoGDI $\alpha$ could interact directly, RhoGDI $\alpha$ was expressed with dual His and T7-tags and passed through a Ni-NTA column to eliminate background before being immobilized on T7-tag beads. The immobilized protein was then incubated with baculovirus-expressed, purified $\mathrm{ER} \alpha$. As seen in Fig. 6B, RhoGDI $\alpha$ and ER $\alpha$ interacted directly in the absence and in the presence of $\mathrm{E}_{2}$ (lanes 4 and 5). Control lanes containing lysate from bacteria, which had been transformed with the parent plasmid instead of RhoGDI $\alpha$ plasmid, failed to interact with ER $\alpha$ (lanes 2 and 3).

\section{RhoGDl $\alpha$ enhances the ER $\alpha$-ERE interaction}

Since ER $\alpha$ interacted directly with RhoGDI $\alpha$, it seemed possible that this interaction might affect the ability of the receptor to bind to its cognate binding site, the ERE. Therefore, gel mobility shift assays were performed using constant amounts of purified ER $\alpha$ and ${ }^{32}$ P-labeled, ERE-containing oligos. As increasing amounts of the purified His-tagged RhoGDI $\alpha$ were added, a slight decrease in the intensity of the band corresponding to ER $\alpha$-ERE binary complex $(\mathrm{C} 1)$ and an increase in the intensity of another, lower mobility 
A

RhoGDl $\alpha$
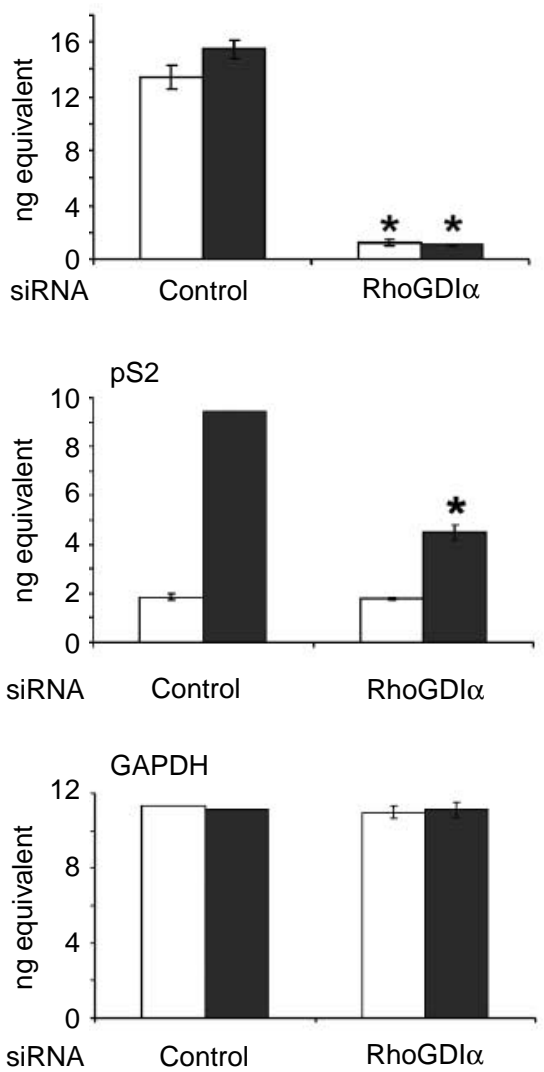
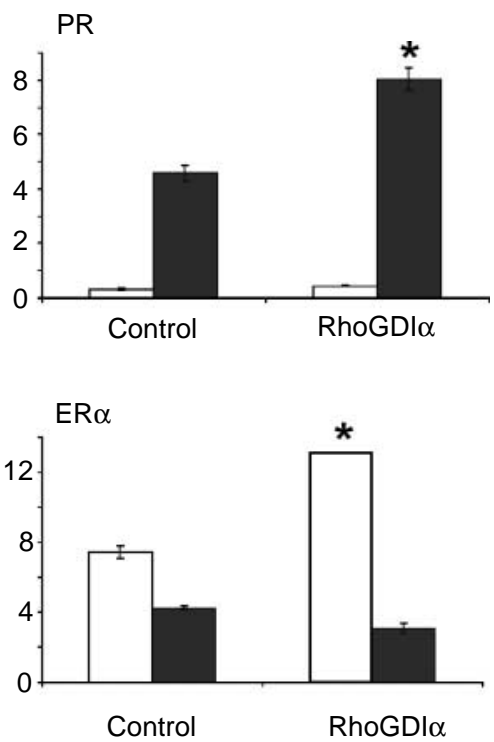

B

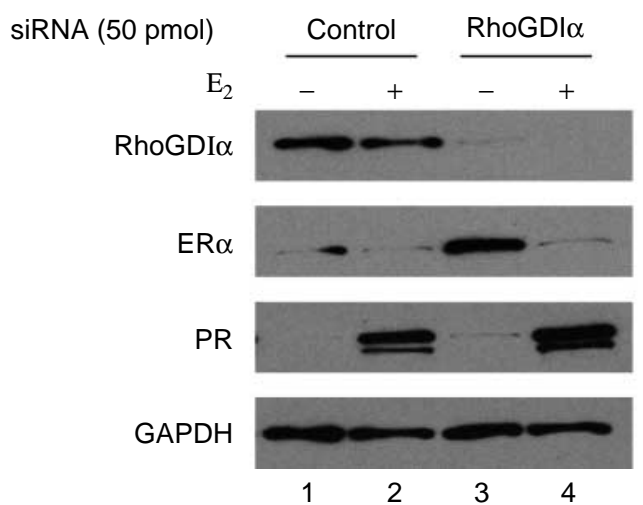

Figure 5 Effect of RhoGDl $\alpha$ on the expression of endogenous, estrogen-responsive genes. MCF-7 cells were transfected with control or RhoGDl $\alpha$-specific siRNA for $24 \mathrm{~h}$ and then treated with ethanol (open bars) or $10 \mathrm{nM} \mathrm{E}_{2}$ (solid bars) for $24 \mathrm{~h}$. (A) RNA was harvested, cDNA was synthesized, and quantitative RT-PCR analysis was performed using primers specific to RhoGDI $\alpha$, PR, pS2, ER $\alpha$, and GAPDH transcripts. Data are reported as the mean of triplicates \pm S.E.M. and is representative of four independent experiments. Some error bars are too small to be visible. An asterisk indicates that the mRNA level detected in the presence of RhoGDI $\alpha$ siRNA was significantly different from the corresponding ethanol or $\mathrm{E}_{2}$-treated sample in the presence of control siRNA as determined by ANOVA $(P \leq 0.05)$. (B) Whole cell extracts were analyzed by western analysis using antibodies specific to RhoGDl $\alpha$, $\mathrm{ER} \alpha, \mathrm{PR}$, and GAPDH. 
A

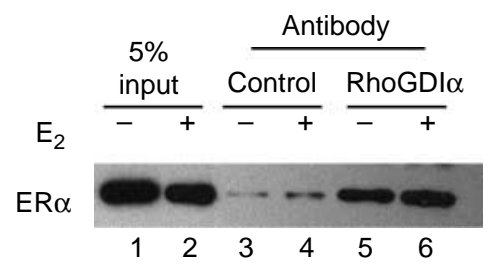

B

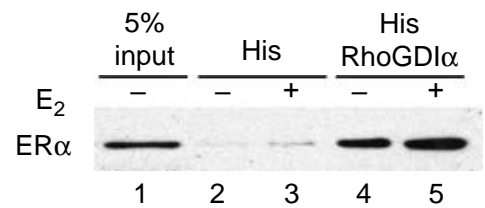

Figure 6 Interaction of RhoGDl $\alpha$ with ER $\alpha$. (A) Whole cell extracts were prepared from MCF-7 cells that had been treated with ethanol or $\mathrm{E}_{2}$ for $24 \mathrm{~h}$ and subjected to immunoprecipitation using antibody directed against fluorescein (control, lanes 3 and 4) or RhoGDI $\alpha$ (lanes 5 and 6). $\mathrm{ER} \alpha$ was detected in western blot analysis with an $\mathrm{ER} \alpha$ specific antibody. (B) Purified ER $\alpha$ was incubated with Ni-NTA purified bacterial lysate (lanes 2 and 3 ) or with Ni-NTA purified His-tagged RhoGDI $\alpha$ (lanes 4 and 5) that had been immobilized on T7-tag beads. Proteins were separated on a denaturing gel and detected with an ER $\alpha$-specific antibody. Five percent input were included for reference. Results are representative of at least three independent experiments.

band (C2) was observed (Fig. 7A, lanes 2-5). As anticipated, the $\mathrm{ER} \alpha$-specific antibody supershifted both $\mathrm{C} 1$ and $\mathrm{C} 2$ (lane 6) demonstrating that ER $\alpha$ was present in both complexes. Curiously, the RhoGDI $\alpha$ antibody not only supershifted C2, which presumably contained the trimeric RhoGDI $\alpha$-ER $\alpha$-ERE complex (lane 7), but also caused the disappearance of C1, which contained the ER $\alpha$-ERE complex. These findings suggest that the RhoGDI $\alpha$-specific antibody fosters the formation of the trimeric RhoGDI $\alpha-\operatorname{Er} \alpha-$ ERE complex and the depletion of the ER $\alpha-E R E$ complex. The ability of an antibody to stabilize the ER $\alpha$-ERE complex has been reported previously and was attributed to the ability of the antibody to enhance receptor dimerization (Fawell et al. 1990). It seems possible that the RhoGDI $\alpha$ antibody could likewise stabilize the association of RhoGDI $\alpha$ and ER $\alpha$ with the ERE-containing DNA. When RhoGDI $\alpha$ was incubated with ERE-containing oligos in the absence of $\mathrm{ER} \alpha$, no complex was observed (lane 8) demonstrating that the formation of the trimeric complex requires the receptor. The ability of the RhoGDI $\alpha$ antibody to supershift the trimeric complex required the presence of RhoGDI $\alpha$ protein as demonstrated by the inability of this antibody to supershift the ER $\alpha$-ERE complex (Fig. 7B, lane 4).

\section{Discussion}

We identified RhoGDI $\alpha$ in a large multiprotein complex associated with the DNA-bound ER $\alpha$ and characterized the ability of this protein to function as a regulator of ER $\alpha$ activity. We have shown that RhoGDI $\alpha$ not only increases $E R \alpha$ transcriptional activity in transient transfection assays but also differentially influences the expression of endogenous estrogenresponsive genes in MCF-7 cells. Our studies suggest that RhoGDI $\alpha$ collaborates with other regulatory proteins to modify the expression of $\mathrm{ER} \alpha$ target genes.

We were initially surprised to find RhoGDI $\alpha$ among the proteins isolated in the protein-ER $\alpha-D N A$ complex, since it has typically been referred to as a cytoplasmic protein (Fukumoto et al. 1990) and we had utilized HeLa nuclear extracts to form our ER $\alpha$ containing multiprotein complexes. However, western blot analysis and ICC assays confirmed the presence of RhoGDI $\alpha$ in the nuclei of MCF-7 cells. A careful examination of RhoGDI $\alpha$ amino acid sequence failed to identify any nuclear localization signal, suggesting that another protein may assist in the shuttling of RhoGDI $\alpha$ between the cytoplasm and the nucleus. It seems plausible that cdc42 isoform1, a RhoGTPase family member with a polybasic region in its C-terminal end that can function as a nuclear localization signal (Lanning et al. 2003, Williams 2003), might perform this function since we identified both isoforms 1 and 2 of cdc42 in our agarose gel purification experiments as ER $\alpha$-associated proteins (Schultz-Norton et al. 2007). Alternatively, RhoGDI $\alpha$ could be accompanied by a protein such as 14-3-3, which binds and helps to redistribute an array of signaling proteins $(\mathrm{Fu}$ et al. 2000, Kino et al. 2003, Diviani et al. 2004). It should also be noted that the $28 \mathrm{kDa}$ RhoGDI $\alpha$ is theoretically small enough to traverse the nuclear pores unaccompanied.

The concentration of RhoGDI $\alpha$ in the nucleolus was unexpected since this nuclear compartment has typically been viewed as the site of rRNA synthesis and ribosome assembly. However, there is accumulating evidence to suggest that nucleolar proteins play a dynamic role in regulating a number of cellular processes including cell cycle progression, cell proliferation, and regulation of gene expression (Weber et al. 1999, Cerutti \& Simanis 2000). It has been suggested that localization of cdc14 in the nucleolus may help to ensure that it is sequestered from its cytoplasmic and nuclear substrates (Bachant \& Elledge 1999). Likewise, the localization of RhoGDI $\alpha$ in the nucleolus may help to simultaneously sequester RhoGDI $\alpha$ from cytoplasmic GTPases and from ER $\alpha$ and at the same time serve as a storage depot to maintain a pool of nuclear RhoGDI $\alpha$ protein that could interact with $\mathrm{ER} \alpha$ and influence gene expression. 

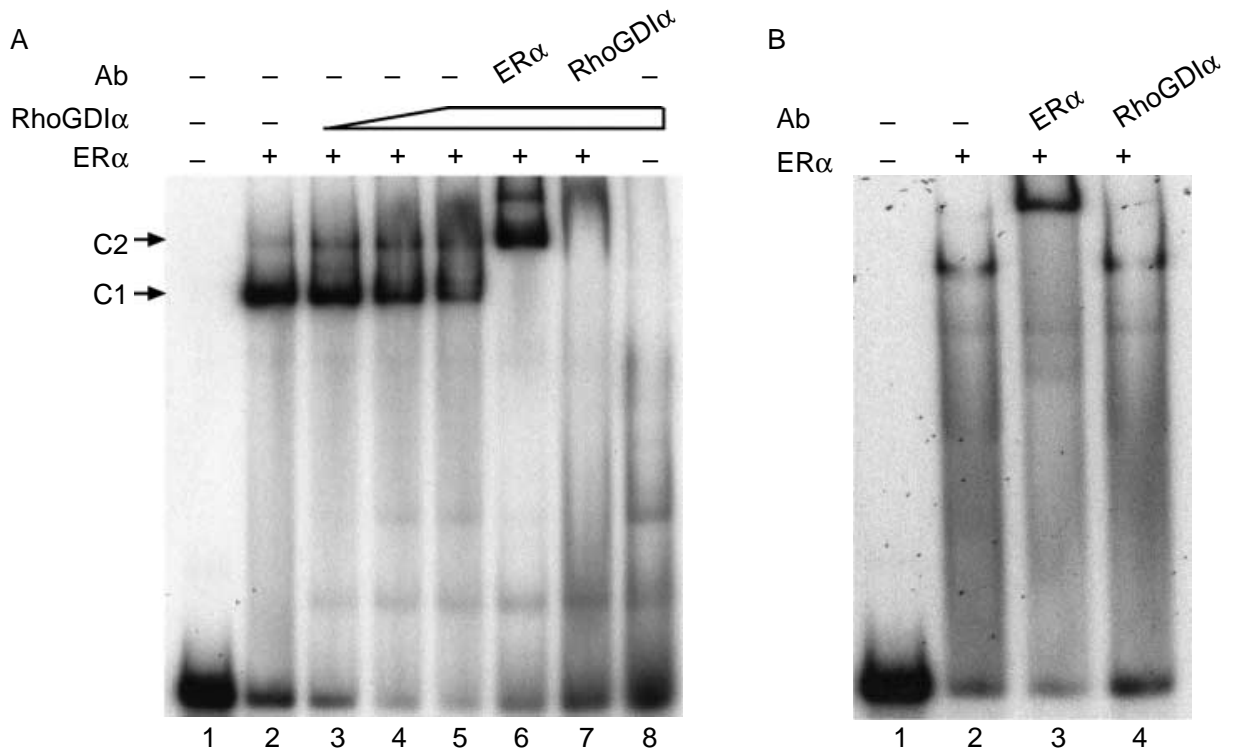

Figure 7 Effect of RhoGDl $\alpha$ on ER $\alpha$-ERE complex formation. (A) Radiolabeled EREcontaining oligos were combined with a constant amount of baculovirus-expressed, purified $\mathrm{ER} \alpha$ (50 fmoles, lanes 2-7) in the absence (lane 2) or in the presence of increasing amounts of RhoGDI $\alpha$ (lane 3, $250 \mathrm{ng}$; lane 4, $500 \mathrm{ng}$; lanes 5, 6, and 7, $1 \mu \mathrm{g}$ ). Antibody (Ab) against $\mathrm{ER} \alpha$ (lane 6) or RhoGDl $\alpha$ (lane 7) was added to the binding reaction as indicated. Lane 8 contains the radiolabeled oligo in the presence of RhoGDl $\alpha(1 \mu \mathrm{g})$ only. B. Radiolabeled EREcontaining oligos were combined with a constant amount of baculovirus-expressed and purified $\mathrm{ER} \alpha$ (50 fmoles, lanes 2-4) in the absence of RhoGDl $\alpha$. Antibody directed against $\mathrm{ER} \alpha$ (lane 3) or RhoGDl $\alpha$ (lane 4) was added to the binding reaction as indicated. Lane 1 contains only radiolabeled, ERE-containing oligos.

The ability of RhoGDI $\alpha$ to alter $\mathrm{ER} \alpha$ activity was previously reported by Garabedian and coworkers (Su et al. 2001), who showed that RhoGDI $\alpha$ enhances $\mathrm{ER} \alpha, \mathrm{ER} \beta$, glucocorticoid receptor and androgen receptor (AR), but not SRF or Sp1, mediated transactivation in transient transfection assays. A subsequent study by this group suggested that RhoGDI $\alpha$ enhances ER $\alpha$ mediated transactivation indirectly through its effects on ER $\alpha$-associated coregulatory proteins ( $\mathrm{Su}$ et al. 2002). In contrast to these studies which proposed that the cytoplasmic RhoGDI $\alpha$ is responsible for altering estrogen-responsive gene expression, our studies provide evidence that nuclear RhoGDI $\alpha$, through its interaction with $\mathrm{ER} \alpha$, also plays a direct role in regulating $\mathrm{ER} \alpha$-mediated transactivation. The presence of RhoGDI $\alpha$ in MCF-7 nuclear extracts, the localization of endogenously expressed RhoGDI $\alpha$ in the nucleus of MCF-7 cells, the coimmunoprecipitation of endogenously expressed RhoGDI $\alpha$ and ER $\alpha$, and the direct interaction of purified ER $\alpha$ and RhoGDI $\alpha$ all support the idea that, in addition to its cytoplasmic activity, nuclear RhoGDI $\alpha$ influences ER $\alpha$ transactivation directly by interacting with the receptor.

As indicated in our siRNA assays (Fig. 5), RhoGDIa differentially modulates the expression of the $P R$ and $p S 2$ genes, which have very different cis elements and trans-acting factors involved in conferring their hormone responsiveness. While the $p S 2$ gene contains an imperfect ERE that interacts directly with ER $\alpha$ (Nunez et al. 1989), the PR gene contains multiple AP-1 and Sp1 sites through which AP-1 and Sp1 proteins interact with ER $\alpha$ (Jeltsch et al. 1987, Petz \& Nardulli 2000, Petz et al. 2002, 2004a,b, Schultz et al. 2003). Thus, we believe that the ability of RhoGDI $\alpha$ to differentially alter estrogen-responsive gene expression may be due to differences in the population of cis elements and the trans-acting factors associated with various target genes.

As might be expected from the effects of RhoGDI $\alpha$ on estrogen-responsive gene expression, this protein is required for fertility and reproductive competence in mice. RhoGDI $\alpha-/-$ males have spermatogenesis defects and are infertile and RhoGDI $\alpha-/-$ females have implantation defects (Togawa et al. 1999). Thus, RhoGDI $\alpha$ not only influences estrogen-responsive gene expression in MCF-7 breast cancer cells, but also has profound effects on the reproductive tract and reproduction.

Interestingly, there is evidence for the involvement of other GTPase regulatory proteins in 
influencing nuclear receptor activity. For example, the GEF protein Brx interacts directly with and enhances the transcriptional activity of ER $\alpha$ (Rubino et al. 1998) and the glucocorticoid receptor (Kino et al. 2006). Vav3, another GEF protein, increases AR-mediated transactivation, but does not appear to interact with the receptor (Lyons \& Burnstein 2006). It is thought that the ability of Vav3 to enhance $A R$ responsiveness may contribute to the relapse of prostate cancer in patients undergoing androgen deprivation therapy (Lyons \& Burnstein 2006). Interestingly, RhoGDI $\alpha$, which opposes the actions of GEFs on RhoGTPases, increases the resistance of cancer cells to chemotherapeutic agents (Zhang et al. 2005).

The ability of RhoGDI $\alpha$ to act as a nuclear receptor coregulatory protein challenges the classical paradigm in which this protein is solely involved in the propagation of signals initiated at the plasma membrane. Our studies suggest that the nuclear actions of RhoGDI $\alpha$ supplement its effects in the cytoplasm and that RhoGDI $\alpha$ functions in both membrane and nuclear signaling pathways.

\section{Acknowledgements}

We are indebted to L Lévesque for assistance with immunocytochemical analysis. We also thank M Garabedian and B Katzenellenbogen for providing plasmids and C Curtis for assistance in preparation of this manuscript. This work was supported by NIH grants RO1 DK 53884 (to A M N) and NIH P41 RR11823 (to J R Y). The authors declare that there is no conflict of interest that would prejudice the impartiality of this scientific work.

\section{References}

Bachant JB \& Elledge SJ 1999 Mitotic treasures in the nucleolus. Nature $398757-758$.

Bunone G, Briand PA, Miksicek RJ \& Picand D 1996 Activation of the unliganded estrogen receptor by EGF involves the MAP kinase pathway and direct phosphorylation. EMBO Journal 15 2174-2183.

Cerutti L \& Simanis V 2000 Controlling the end of the cell cycle. Current Opinion in Genetics and Development 10 65-69.

Chodosh LA \& Buratowski S 1989 Mobility shift DNA-binding assay using gel electrophoresis. In Current Protocols in Molecular Biology, pp 12.12.11-12.12.10. Eds FM Ausubel, R Brent, RE Kingston, DD Moore, JG Seidman, JA Smith \& K Struhl. New York: Greene Publishing Associates and Wiley Interscience.

Diviani D, Abuin L, Cotecchia S \& Pansier L 2004 Anchoring of both PKA and 14-3-3 inhibits the Rho-GEF activity of the AKAP-Lbc signaling complex. EMBO Journal 23 2811-2820.

Fawell SE, White R, Hoare S, Sydenham M, Page M \& Parker MG 1990 Inhibition of estrogen receptor-DNA binding by the 'pure' antiestrogen ICI 164384 appears to be mediated by impaired receptor dimerization. PNAS $\mathbf{8 7} 6883-6887$.
Fu H, Subramanian RR \& Masters SC 2000 14-3-3 Proteins: structure, function, and regulation. Annual Review of Pharmacology and Toxicology 40 617-647.

Fukumoto Y, Kaibuchi K, Hori Y, Fujioka H, Araki S, Ueda T, Kikuchi A \& Takai Y 1990 Molecular cloning and characterization of a novel type of regulatory protein (GDI) for the rho proteins, ras p21-like small GTP-binding proteins. Oncogene 5 1321-1328.

Hart MJ, Maru Y, Leonard D, Witte ON, Evans T \& Cerione RA 1992 A GDP dissociation inhibitor that serves as a GTPase inhibitor for the Ras-like protein CDC42Hs. Science 258 812-815.

Ignar-Trowbridge DM, Teng CT, Ross KA, Parker MG, Korach KS \& McLachlan JA 1993 Peptide growth factors elicit estrogen receptordependent transcriptional activation of an estrogen-responsive element. Molecular Endocrinology 7 992-998.

Jeltsch JM, Roberts M, Schatz C, Garnier JM, Brown AMC \& Chambon P 1987 Structure of the human oestrogen-responsive gene $p S 2$. Nucleic Acid Research 15 1401-1414.

Kato S, Endoh H, Mashuhiro Y, Kitamoto T, Uchiyama S, Sasaki H, Masushige S, Gotoh Y, Nishida E, Kawashima H et al. 1995 Activation of the estrogen receptor through phosphorylation by mitogenactivated protein kinase. Science 270 1491-1494.

Kim J, Petz LN, Ziegler YS, Wood JR, Potthoff SJ \& Nardulli AM 2000 Regulation of the estrogen-responsive $p S 2$ gene in MCF-7 human breast cancer cells. Journal of Steroid Biochemistry and Molecular Biology 74 157-168.

Kino T, Souvatzoglou E, De Martino MU, Tsopanomihalu M, Wan Y \& Chrousos GP 2003 Protein 14-3-3 sigma interacts with and favors cytoplasmic subcellular localization of the glucocorticoid receptor, acting as a negative regulator of the glucocorticoid signaling pathway. Journal of Biological Chemistry 278 25651-25656.

Kino T, Souvatzoglou E, Charmandari E, Ichijo T, Driggers P, Mayers C, Alatsatianos A, Manoli I, Westphal H, Chrousos GP et al. 2006 Rho family Guanine nucleotide exchange factor Brx couples extracellular signals to the glucocorticoid signaling system. Journal of Biological Chemistry 281 9118-9126.

Koch G, Tanaka K, Masuda T, Yamochi W, Nonaka H \& Takai Y 1997 Association of the Rho family small GTP-binding proteins with Rho GDP dissociation inhibitor (Rho GDI) in Saccharomyces cerevisiae. Oncogene 15 417-422.

Lanning CC, Ruiz-Velasco R \& Williams CL 2003 Novel mechanism of the co-regulation of nuclear transport of SmgGDS and Rac1. Journal of Biological Chemistry 278 12495-12506.

Leonard D, Hart MJ, Platko JV, Eva A, Henzel W, Evans T \& Cerione RA 1992 The identification and characterization of a GDP-dissociation inhibitor (GDI) for the CDC42Hs protein. Journal of Biological Chemistry 267 22860-22868.

Loven MA, Muster N, Yates JR \& Nardulli AM 2003 A novel estrogen receptor $\alpha$-associated protein, template activating factor $\mathrm{I} \beta$, inhibits acetylation and transactivation. Molecular Endocrinology 17 67-78.

Lyons LS \& Burnstein KL 2006 Vav3, a Rho GTPase guanine nucleotide exchange factor, increases during progression to androgen independence in prostate cancer cells and potentiates androgen receptor transcriptional activity. Molecular Endocrinology 20 1061-1072.

Ma ZQ, Santagati S, Patrone C, Pollio G, Vegeto E \& Maggi A 1994 Insulin-like growth factors activate estrogen receptor to control the growth and differentiation of the human neuroblastoma cell line SK-ER3. Molecular Endocrinology 8 910-918.

Masuda T, Tanaka K, Nonaka H, Yamochi W, Maeda A \& Takai Y 1994 Molecular cloning and characterization of yeast rho GDP dissociation inhibitor. Journal of Biological Chemistry 269 19713-19718.

Nardulli AM, Greene GL, O'Malley BW \& Katzenellenbogen BS 1988 Regulation of progesterone receptor messenger ribonucleic acid and protein levels in MCF-7 cells by estradiol: analysis of estrogen's effect on progesterone receptor synthesis and degradation. Endocrinology 122 935-944.

Nunez A-M, Berry M, Imler J-L \& Chambon P 1989 The $5^{\prime}$ flanking region of the $p S 2$ gene contains a complex enhancer region 
responsive to oestrogens, epidermal growth factor, a tumour promoter (TPA), the c-Ha-ras oncoprotein and the c-jun protein. EMBO Journal 8 823-829.

Olofsson B 1999 Rho guanine dissociation inhibitors: pivitol molecules in cellular signalling. Cell Signaling 11 545-554.

Petz LN \& Nardulli AM 2000 Spl binding sites and an estrogen resonse element half-site are involved in regulation of the human progesterone receptor A promoter. Molecular Endocrinology 14 972-985.

Petz LN, Ziegler YS, Loven MA \& Nardulli AM 2002 Estrogen receptor alpha and activating protein-1 mediate estrogen responsiveness of the progesterone receptor gene in MCF-7 breast cancer cells. Endocrinology $1434583-4591$.

Petz LN, Ziegler YS, Schultz JR \& Nardulli AM 2004a Fos and Jun inhibit estrogen-induced transcription of the human progesterone receptor gene through an activator protein-1 site. Molecular Endocrinology 18 521-532.

Petz LN, Ziegler YS, Schultz JR, Kim H, Kemper JK \& Nardulli AM $2004 b$ Differential regulation of the human progesterone receptor gene by an estrogen response element half site and Sp1 sites. Journal of Steroid Biochemistry and Molecular Biology $\mathbf{8 8}$ 113-122.

Reese JC \& Katzenellenbogen BS 1991 Differential DNA-binding abilities of estrogen receptor occupied with two classes of antiestrogens: studies using human estrogen receptor overexpressed in mammalian cells. Nucleic Acid Research 19 $6595-6602$.

Rubino D, Driggers P, Arbit D, Kemp L, Miller B, Coso O, Pagliai K, Gray K, Gutkind S \& Segars J 1998 Characterization of Brx, a novel Dbl family member that modulates estrogen receptor action. Oncogene 16 2513-2526.

Schultz JR, Petz LN \& Nardulli AM 2003 Estrogen receptor $\alpha$ and Sp1 regulate progesterone receptor gene expression. Molecular and Cellular Endocrinology 201 165-175.
Schultz-Norton JR, Walt KA, Ziegler YS, McLeod IX, Yates JR, Raetzman LT \& Nardulli AM 2007 The DNA repair protein flap endonuclease-1 (FEN-1) modulates estrogen-responsive gene expression. Molecular Endocrinology 21 1569-1580.

Su LF, Knoblauch KA \& Garabedian MJ 2001 Rho GTPases as modulators of the estrogen receptor transcriptional response. Journal of Biological Chemistry 276 3231-3237.

Su LF, Wang Z \& Garabedian MJ 2002 Regulation of GRIP1 and CBP Coactivator activity by Rho GDI modulates estrogen receptor transcriptional enhancement. Journal of Biological Chemistry 277 37037-37044

Togawa A, Miyoshi J, Ishizaki H, Tanaka M, Takakura A, Nishioka H, Yoshida H, Doi T, Mizoguchi A, Matsuura N et al. 1999 Progressive impairment of kidneys and reproductive organs in mice lacking Rho GDI $\alpha$. Oncogene 18 5373-5380.

Weber JD, Taylor LJ, Roussel MF, Sherr CJ \& Bar-Sagi D 1999 Nucleolar Arf sequesters Mdm2 and activates p53. Nature Cell Biology 1 20-26.

Williams CL 2003 The polybasic region of Ras and Rho family small GTPases: a regulator of protein interactions and membrane association and a site of nuclear localization signal sequences. Cell Signalling 15 1071-1080.

Wood JR, Likhite VS, Loven MA \& Nardulli AM 2001 Allosteric modulation of estrogen receptor conformation by different estrogen response elements. Molecular Endocrinology 15 1114-1126.

Zhang B, Zhang Y, Dagher MC \& Shacter E 2005 Rho GDP dissociation inhibitor protects cancer cells against drug-induced apoptosis. Cancer Research 65 6054-6062.

Received in final form 3 July 2007

Accepted 30 July 2007

Made available online as an Accepted Preprint 2 August 2007 